the field. We segregate the blood still further by binding the lower extremities at the groin with Martin's elastic bandages applied tight enough to prevent the return circulation. We record the blood-pressure, taken in the arm, at intervals during the operation, and find that it falls usually from 20 to $40 \mathrm{~mm}$. This position and segregation minimizes the hemorrhage, gives nearly a dry field and brings the patient up nearer to the operator. In relation to extending the incision to the mouth in an upward curve, as has been suggested by one speaker, one needs to be careful not to carry this curve too far. In an instance of which I have knowledge the patient wore a goatee following the operation. These upward curves may have affected his disposition pleasantly, as in the speaker's case, but he certainly looked like the devil.

Dr. W. Lemoyne Wills, Los Angeles, Cal.: If there is anything that the surgeon needs to have drilled into him it is anatomy. Surgeons are more apt to ignore the anatomy than their knowledge justifies. We all know how uncomfortable an ill fitting armhole of a coat is and so is a scarred axilla bolding the arm down to the chest. We should give this matter considerably more attention. Therefore, Dr. Jackson's paper is a most timely one, and future officers of this section should encourage the presentation of such papers.

Dr. John C. Munro, Boston: Dr. Jackson's principle we have used with the greatest satisfaction. Even though we are extending it as he suggested in his remarks to the modification that Handley suggested yet the principle still lies there in his flap and it has been of great help in carrying out our work.

Dr. Marcell Hartwig, Buffalo, N. Y.: I do not believe that a man will look like the devil if the surgeon transfers a good chunk of the upper lip. In my experience there is no more perfect and beautiful mouth to be made than if the muco. cutaneous edge of the upper lip be used, of course, including the supplying artery. If much of the lower lip or all of it has been lost one can make a very nice mouth by cutting horizontally one-half of the side of the upper lip and stretching it toward the center of the lower lip, doing the same on the other side. That gives the patient a good mouth and there is no trouble with hair growing inside the mouth, as I saw in a case in which the late Dr. Post had used the skin of the chin. Has Dr. Jackson ever operated in a case in which the arm was swollen? I would urge pathologists to examine every case of death from other diseases and see whether infection is transmissible through the lymph nodes. We ought to know $\epsilon$ xactly when the first infection of the glands oceurs. I am inclined to believe that it occurs almost instantaneously.

DR. J. C. STEWART, Minneapolis: In operations for cancer of the breast has it been observed that recurrences have changed their position since the adoption of the Willy Meyer, Jackson and other operations in the axilla? It seems to me that when we did the Halsted operation there were more recurrences in the axilla and that since we began to operate from the axilla there have been more recurrences over the lower portion of the field of operation. That may be a mistaken observation, but it appears to be true, and, if so, it demonstrates that the handling and manipulation of the breast and other cancer tissues during the operation drives the cancer material toward the lymphatics in the direction where the structure was last severed from its connection with the body. It seems to me that there is more danger from the dissemination of eancers by rough handling than by transplantation. Dr. Binnie's observations on the lymphatics would seem of rather theoretical value, as he must admit the passage of cancer cells through them on their way to the nodes and his inability to specify any tissues when the lymph channels are surely free from such cancer cells.

Dr. J. N. JAckson, Kansas City, Mo.: Some years ago in reading a paper on traumatic surgery $I$ said that true conservatism is that which puts life first, then function and then form. That rule should be observed particularly in such conditions as cancer of the breast. The first aim in the diagnosis or treatment of suspicious cases is to know whether the dis ease is cancer as early as possible, and if it is, beyond any question, get right after it. When we recall that 90 per cent of tumors of the breast are malignant or ultimately become so, there is no excuse for delay in operation. I believe that in doubtful cases the immediate diagnosis by operation should be insisted on in every instance. I further believe, however, that knowing the statistics of the general probabilities, if we are unable to make an absolute diagnosis, the patient should be given the benefit of the doubt as to life and a radical operation should be done. In nine cases out of ten the patient's life is jeopardized by waiting. I know of eases in which conservative work was done and the patient came to me later with a malignant disease which terminated fatally even after radical operation. I would not advocate any operation for cancer which in any way restricts the field of radicalism that gives the patient the best chance for an ultimate recovery. My one argument is that in this operation the removal is as extensive as can be suggested by any operation. If we can preserve life and function we have two elements of conservative surgery, and $I$ believe that my operation gives better function than any other. And, finally, if we can preserve life, form and function this should be done. Thoroughness of surgery should not be sacrificed for the art of surgery, but where art and science can be combined this should be done. I fear that we have gone too mueh to the scientific side and have overlooked art.

Dr. Grant's method of operation for cancer of the lip escaped my attention until about six months ago and since then $I$ have had two cases in which I have been able to carry out the method. It certainly does what he claims for it, so far as complete removal of the growth and the lymph glands is concerned, and it also gives a beautiful cosmetic effect. It far surpasses any operation for cancer of the lip in thoroughness and final results. An important feature of the operation is the fact that the chin, which is not involved in the disease, is left as a base on which the new lip is reconstructed. It gives a lip which is natural in appearance and does not draw down. Dr. Stewart makes his incision upward when there is opportunity to enlarge the mouth. Dr. Grant says to make the incision downward, and my observation coincides with this. At one operation I had a dispute with a friend as to which direction the incision should take. I did it downward on one side and upward on the other. If the levator muscle is left unopposed it draws the lip up and our patient had a mouth which was rather ludicrous. When the ineision is made slightly downward there is equalization of opposing muscles and the mouth is straight and it has a normal contour. That is an important point to bear in mind.

\section{PALATOPHARYNGEAL ADHESIONS}

METHODS ADOPTED FOR THEIR RELIEF, WITH THE REPORT OF A NEW OPERATION *

$$
\text { JOHN O. ROE, M.D. }
$$$$
\text { ROCHESTER, N. } Y \text {. }
$$

There is no one malady, not immediately dangerous to life, that so seriously afflicts the person possessing it as adherence of the palate to the pharyngeal wall. When we consider its baneful effects on nearly all the functions of the upper air passages, on respiration, vocalization, hearing, smell, taste and deglutition, and the very disappointing results so frequently attending the attempts at its relief, it is remarkable that operative measures have not long since been devised affording a reasonable cert:uinty of success in such unsatisfactory cases.

Adhesions of the palate or pillars to the posterior pharyngeal wall present a variety of conditions, which may be differentiated as follows:

1. Adhesion of the normal palate or pillar, or both, to an ulcerated pharynx.

2. Adhesion of an ulcerated palate or pillar, or both to a normal pharynx.

* Read in the Section on Laryngology and Otology of the American Medical Association, at the Sixtieth Annual Session, held at Atlantic City, Inne, 1909. Considerations of space compel the abbreviation of this article in THE Jolinxal by omitting part of the case reports. The complete article may be found in the Transactions of the Section and in the author's reprints. 
3. Adhesions of both an ulcerated palate or pillar, or both, to an ulcerated pharynx.

4. Adhesion of one pillar and one side of the palate to the pharynx.

5. Adhesion of the border of the palate to the pharynx except a small opening in the center.

6. Adhesion of the entire soft palate to the pharynx. the one merging imperceptibly into the other.

7. Adhesion with marked cicatricial thickening, contraction, distortion and narrowing of the entire pharynx, or of the entire palate or of both.

8. Association of the latter condition with cicatricial adhesions to the base of the tongue or to the larynx, or both.

Numerous cases are reported illustrating the great variety, both as to extent and location, of these adhesions, from the simple attachment of one pillar or a portion of the palate to the plarynx, to the adherence or

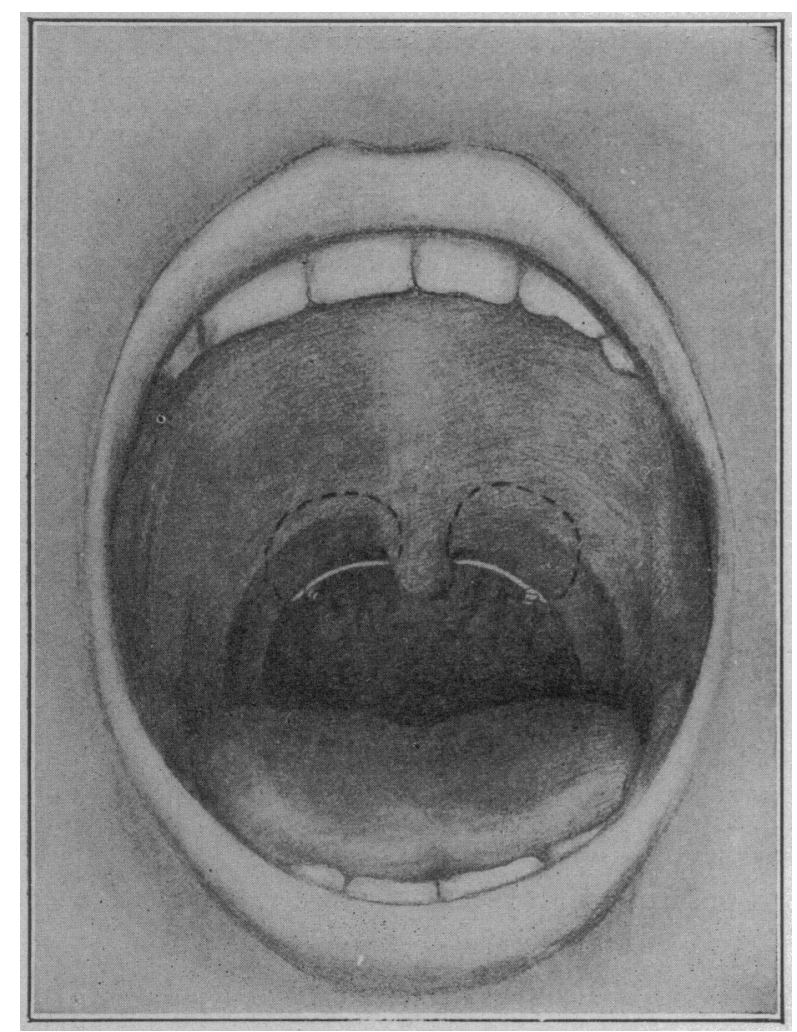

Fig. 1.-Two rings of sllver wire, the dotted lines indicating their location, passing out through opening in center under uvula Cases 1 and 3 .

growing together of all the different tissues of the nasopharynx and fauces. Among some of these latter cases illustrating the severity of the disturbance that may be caused thereby I mention the following:

Vansant ${ }^{1}$ reports a case of extensive syphilitic cicatricial adhesions of the tongue to the inner surfaces of the gums, to the roof of the mouth, and to the palate and pharyngeal wall. The constriction of the fauces was so great and respiration and deglutition became so extremely difficult that during the years 1889 and 1890 four extensive operations were performed, excising the cicatricial tissue, but to no avail, the cicatricial tissue being replaced and the constriction returning in about six weeks. Tracheotomy was advised but refused, and the patient finally died of inanition and exhaustion.

E. Harrison Griffin ${ }^{2}$ reports a case (the patient, a man, aged 44, who had had syphilis twenty years pre-

1. Vansant: Med. News, Philadelphia, 1894, 1xv, 606. viously) in which the palate was destroyed, the remaining stump being firmly adherent to the pharynx. The nose was destroyed to the level of the face. The patient's mouth was so closed by syphilitic adhesions that only two fingers could be passed with great difficulty, by stretchings: the mouth to its utmost capacity. $\mathrm{He}$ was corhhlyletyis ohonic. In this case there was complete separation of the two pharynges by these membranous and cicatricial adhesions.

Lublinski ${ }^{3}$ and Largreuter ${ }^{4}$ report.cases in which the cicatrix so involved the pillars of the fauces, base of the tongue and soft palate as to cause a ring of tissue just above the larynx that so obstructed respiration as to require tracheotomy. Gerhart ${ }^{5}$ reports a case in which a diaphragm formed just above the larynx that would scarcely admit the tip of the finger.

\section{ETIOLOGY}

Palatopharyngeal adhesions may be (1) congenital; (2) simple inflammatory-catarrhal; (3) the result of excoriation of the mucous membrane from acrid discharges; (4) local manifestations of the exanthemata; (5) local manifestations of constitutional diseases, as tuberculosis, syphilis, hereditary or acquired, and "socalled" scrofula; (6) traumatism.

$\mathrm{Hall}^{6}$ reports the case of two children, aged 6 and 11 , who had been sent to him by the medical inspector of schools to be operated on for adenoids. No adenoids were found, but in both cases adhesions of the palate to the pharynx were discoverea to be the cause of the trouble, which undoubtedly were congenital. These adhesions on being broken up with the finger gave the sensation like that of an adherent placenta.

In one case, that of a child 18 months old, which came under my observation, in consultation, there was complete adherence of the palate associated with complete bony occlusion of the posterior nares.

Contrary to the opinion of Lieven, ${ }^{7}$ that there must of necessity have been two ulcerated surfaces opposing each other, Ried ${ }^{8}$ observes that simple inflammatory or catarrhal inflammation, in which plastic lymph is thrown out on the surface, may readily cause adherence of the two surfaces. Schech ${ }^{9}$ observes that adhesions may follow the superficial erosion from simple desquamation of the epithelium, and Lavrand ${ }^{10}$ mentions a case of catarrhal ulceration of the pharynx which was followed by adhesion. This case, which he speaks of as having a scrofulous basis, was in all probability luetic.

The same condition of catarrhal inflammation, however, may be caused by acrid discharges from ulcerated surfaces, from the accessory sinuses, or from other chronic inflammatory conditions. In the case of gummy deposits, which most often take place in the posterior pharyngeal wall, the breaking down of this material and the formation of ulcerated surfaces in this wall with their attendant discharges account for the readiness with which the palate becomes denuded of its epithelium, and, as the ulceration in the pharyngeal wall heals, adherence of the two surfaces takes place. The adherence in these cases is also aided by gravity when the patient is in the recumbent position, and also by the impairment of the action of the pharyngeal dilators, by the inflam-

3. Lublinski : Berl. klin. Wehnschr., 1883, $\mathrm{xx}, 361$.

4. Largreuter: Arch. f. klin. Med., 1880, xxvii, 328

5. Gerhart: Virchows Arch. f. path. Anat., $x \times 1,40$.

6. Hall : Brit. Med. Jour., 1909, 1, 18.

7. Lieven: München. med. Wchnschr., 1895, xIli, 489

8. Ried : Jenaische Ztschr. f. Med., u Naturu. Leipz., 1864, 1, 409

9. Schech: Deutsch. Arch. f. klin. Med., 1875, xvili, 75.

10. Lavrand: Jour. Soc. méd. de Lille, 1891, ii, 361. 
matory process, or the luetic poison, as was pointed out by Neumann. ${ }^{11}$

Local manifestations of the exanthemata may in the same manner produce a condition favoring adherence of the parts. Albertin ${ }^{12}$ mentions a case of adhesion of the palate to the posterior wall of the pharynx taking place after variola. MacMahon, ${ }^{13}$ Symanowski $^{14}$ and Ingals ${ }^{15}$ report cases following diphtheria; such a case, presently to be reported, has also come under my observation.

of the constitutional conditions which may cause palatal adhesions we find cases of lupus and rhinoscleroma reported by $\mathrm{Cartaz}^{16}$ and Castex; ${ }^{17}$ Mikulicz $^{18}$ reports cases following leprosy; Dieffenbach ${ }^{10}$ and Paul ${ }^{20}$ report cases following scrofulous ulceration, and Volkmann"1 has observed it following tuberculous ulceration of the pharynx. This must be rare, as tuberculous ulcerations of the pharynx show but little inclination to heal.

Among the traumatic causes we may mention gunshot wounds, substances accidentally driven through the mouth, laceration of the fauces during surgical operations, and the use of caustics and the galvanocautery. $W$ alb $^{22}$ reports the occurrence of marked stenosis of the throat and adhesions of the soft palate in several cases resulting from a too vigorous and unskilful use of the galvanic and Paquelin cautery in the hands of surgeons and throat specialists. Hamilton ${ }^{23}$ mentioned a case which came under his observation in which the excessive use of the galvanic cautery caused adhesions of the posterior pillars to the pharyngeal wall.

An interesting case of adhesion of the palate to the pharynx following laceration during a surgical operation came under my observation recently and will presently be described.

By far the largest number of cases, however, are caused by tertiary syphilis. Paul, ${ }^{20}$ of Breslau, observed 30 cases of adherent palate; 26 of them were caused by tertiary syphilis and 4 by scrofula. Cartaz ${ }^{16}$ is of the opinion that all cases of total adhesion resulting from ulcerative processes are due to syphilis. He collected reports of 39 cases, 32 of which were ascribed to syphilis and 5 to malignant scrofula, which Cartaz believed to be syphilis, and to which all doubtful cases are to be ascribed. According to Schwebisch, ${ }^{24}$ syphilitic adhesions are more frequent among men, while those resulting from scrofula are more frequent among women.

\section{CHARACTERISTICS AND RESULTS OF THE LESIONS}

The distinctive difference between adhesions due to syphilis and the other causes mentioned is that the former is usually characterized by marked cicatricial contraction, the result of the extensive destruction of tissue; while the adhesions resulting from other conditions aro usually of a simple character, as if the parts were glued or had grown together, and are unattended with marked distortion. In all syphilitic cases the central point of the stricture is located where there has been the largest deposit of gummy material, and consequently the greatest

11. Neumann: Berl. klin. Wehnschr., February 8, 1892

12. Albertin: Monatschr. f. Ohrenh., 1894, p. 196.

13. MacMahon: Internat. Centralbl. f. Laryngol., 1891, No. 5 ; Canadian Pract., February 16, 1891.

14. Symanowski : Vrtljschr. f. d. prakt. Heilk., 1864, Ixxxii, 142

14. Symanowski : Vrtljschr. f. d. prakt. Heilk., 1864,
15. Ingals : Tr. Am. Laryngol. Assn., 1883, p. 188.

16. Cartaz: Arch. internat. de laryngol., 1893, vi, No. 2

16. Cartaz: Arch. internat. de laryngol

18. Mikulicz and Michelson: Atlas der Krankheiten der Mundund Rachenhöble.

19. Dieffenbach: Operative Chirurgie, Vol. i

20. Paul : Arch, f. klin. Chir., vii, 195

21. Volkmann : München. med. Wchnschr., 1895, xlii, 489.

22. Walb: Ztschr. f. Ohrenh., 1889-90, $x x, 60$.

23. Hamilton: Montreal Med. Jour. 1895, xxiii, 193.

24. Schwebisch : Thèse de Paris, 1880. amount of ulceration. as shown by the direction of the contraction or distortions of the palate and uvula, when the latter has not been destroyed. When the uvula has been destroyed, the palate coalescing with the pharynx, the former must have been the seat of the primary deposit associated with that in the pharynx. This latter condition, as Scheck ${ }^{2 \overline{ }}$ observes, is frequently associated with perforation of the palate, which drops back and unites with the pharynx as soon as the opening occurs.

Ulceration followed by adhesions frequently takes place in tissues hidden from view behind the velum; and, as it usually is not attended with a great degree of pain or soreness, the onset of the trouble is often overlooked and the mischief produced before the ulceration has been suspected. Hamilton and Lichtwet ${ }^{26}$ report cases in which the adhesion was revealed only by the rhinoscope and digital examination.

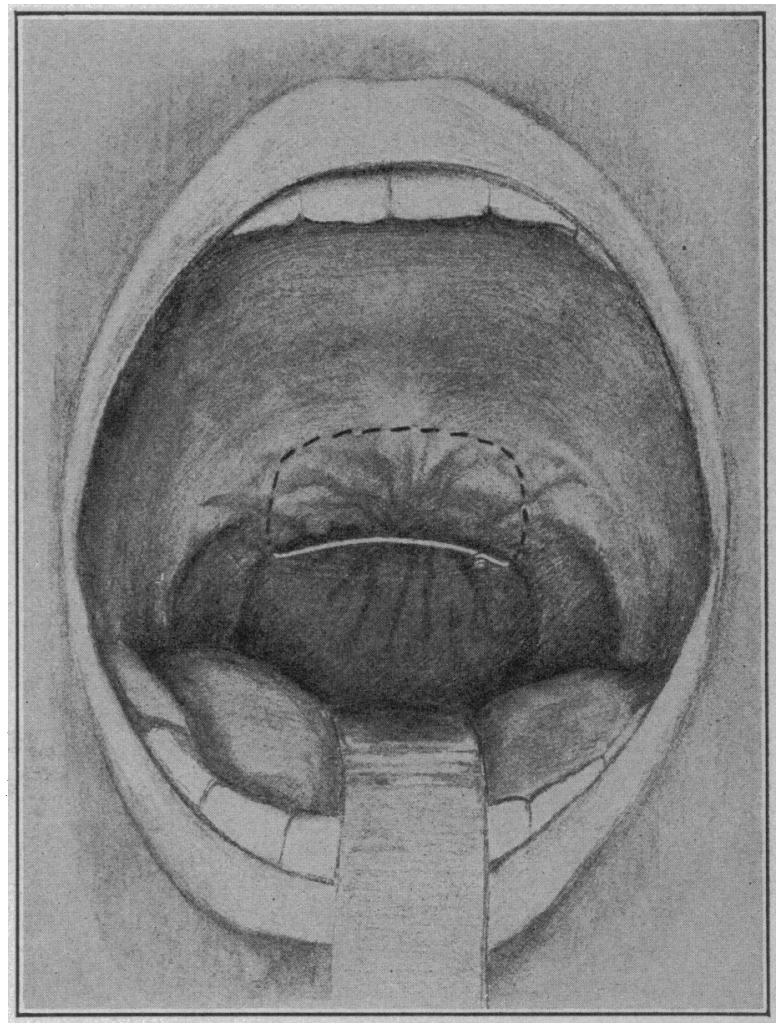

Fig. 2.-Single ring of silver wire, the dotted line indicating its passage above the adhesion behind the palate; Case 2 .

Considering the frequency of such erosion, adhesion of the palate would doubtless be of much more frequent occurrence were it not for the movements of the muscles and the motions of the parts during the act of swallowing, speaking, breathing, and more or less the motions of the body, and also the separation of the parts by the mucus discharging from the posterior nares. Paul ${ }^{20}$ called attention to this fact and also to the readiness and rapidity with which the adhesions take place when perforation of the palate occurs, doing away with these hindrances to union to a large extent. It is rare that ulceration of both the palate and pharynx take place at the same time, the gummy deposit being located in one or the other of these parts. The location of the deformity and the direction of the contraction, therefore, indicate the primary location of the deposit and

25. Scheck: Arch. f. klin. Med., 1876, xvil, 59.

26. Hamilton: Montreal Med. Jour., 1895, xxiii, 191; Lichwetz Ann. d. mal, de l'oreille et du larynx, 1894, xx, 815 . 
the site of the greatest destruction of tissue as observed by Bosworth. ${ }^{2 \pi}$

Dr. Andrew H. Smith ${ }^{2 s}$ has appropriately likened the process of palatal adhesions to that of burns between fingers. In such cases reunion is certain to take place after liberation and even after cicatrization, if a small granulating space is left at the point where they join, as it will creep along each finger, destroying the newlyformed cicatrix, while adhesion of the opposed raw surfaces will advance at a corresponding pace. The same process is also to be observed after the liberation of webbed fingers.

In some cases the adherence of the velum to the pharywx takes place at many and different points, as described by Homolle, ${ }^{29}$ instead of being progressive from the sides, as is usually the case, leaving a small opening in the center. In other cases, however, the adherence of

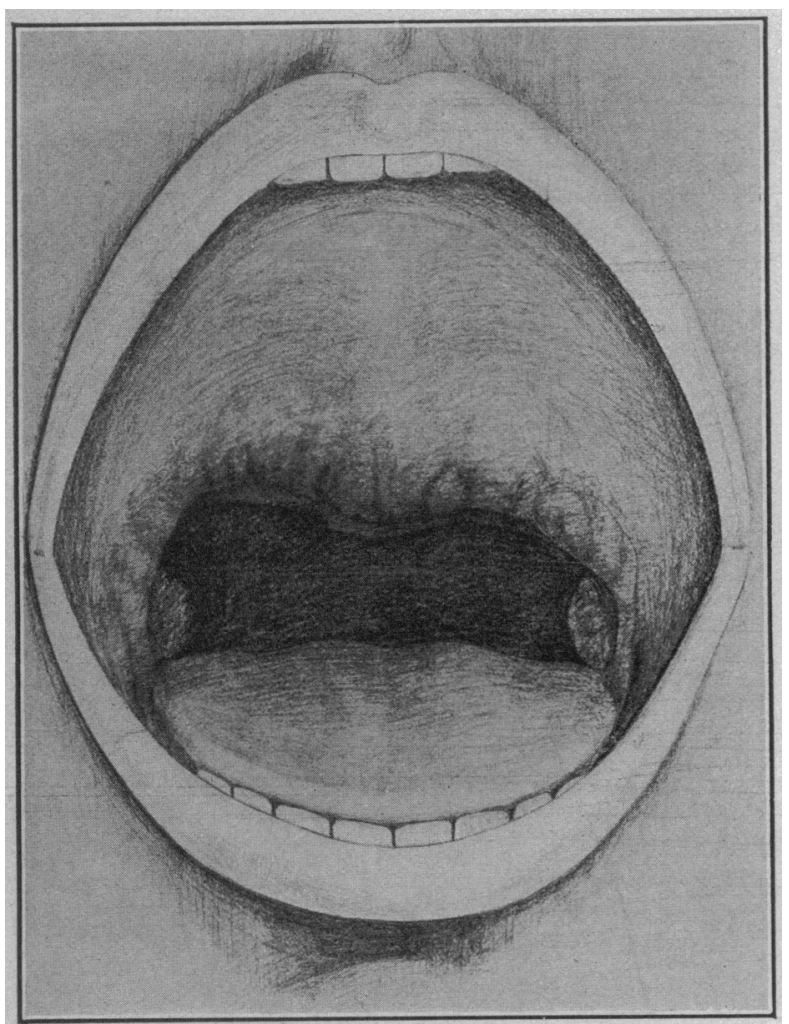

Fig. 3.-Indurated condition of fauces with adhesion of palate to pharynx--tonsils unlemoved; Case 4

the entire palate seems to take place simultaneously when there is an extensive ulceration resulting from the deposits of gummy material in the different structures and breaking down at the same time.

The rapidity with which the adhesion takes place toward the close of the healing of the ulceration is sometimes truly surprising, often two or three days only elapsing from the time a free opening is observed until it is found closed.

Complete union of the palate to the pharynx is the exception rather than the rule, for it is rare that a small opening can not be found through which a slender probe can be passed. This coincides with the experience of Bosworth, Rice, Cartaz and some others, and, judging from the imperfect reports of many cases, it seems quite probable that a more careful examination would have re-

27. Bosworth: Diseases of the Nose and Throat, New York, 1892 , ii, 280 .

28. Smith, A. H. : Tr. Am. Laryngol. Assn., 1883, p. 187.

29. Homolle: Thèse de I'aris, 1875 . vealed a small opening. Of the 30 cases reported by Paul, ${ }^{30}$ there was total adherence of the palate in 3 only. Bosworth $^{2 \pi}$ collected reports of 45 cases, of which 19 were reported as being total, while 26 were partial adhesion of the palate.

Regarding the local disturbances caused by these adhesions Hajek ${ }^{31}$ very truly says:

While the partial adhesion of the soft palate and the back wall of the throat seldom give much trouble, the total elosing of the space between the throat and the nose is accompanied by grave consequences. The impossibility of breathing through the nose, necessitating therefore continual opening of the mouth and the subsequent dryness of the throat, the inability to blow the nose, the accumulation of secretions in the nasal passages, often becoming fetid; the frequently associated ear troubles and consequent deafness. the sleeplessness and marked eftect on the general health make this condition well-nigh

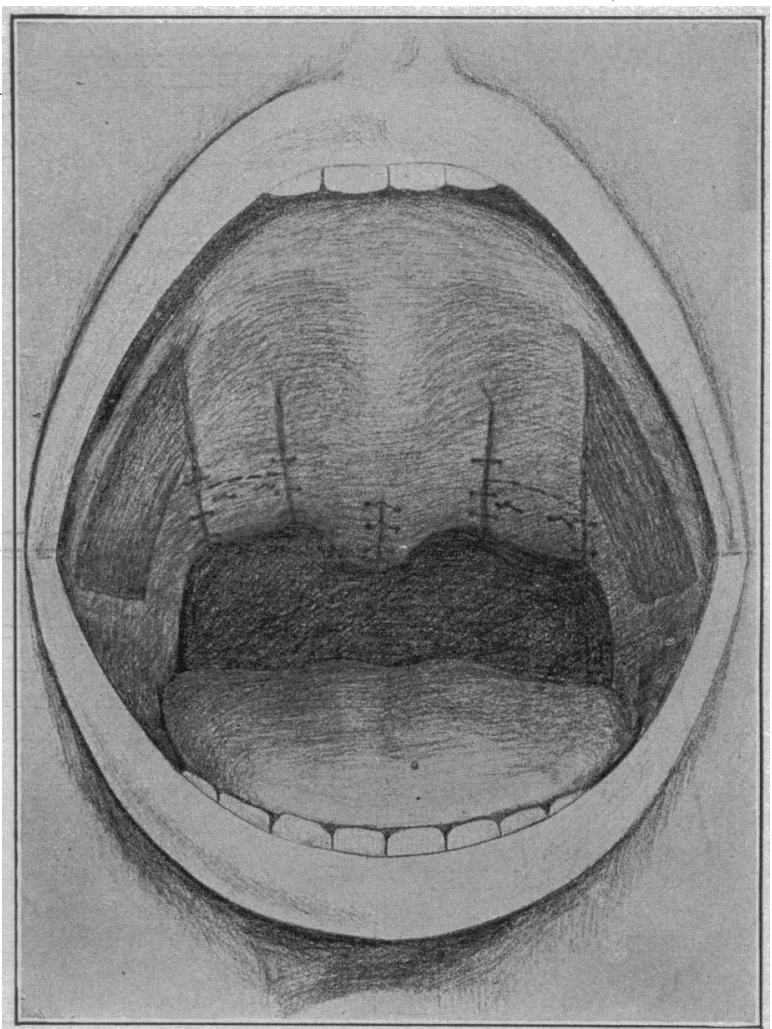

Fig. 4.-Flaps stitched after liberation of palate. Location at sides from which flaps were taken tonsils removed; Case 4.

unbearable and make on the surgeon the most urgent de mands for its relief.

When the closure of the postnasal opening, however, is sufficient to prevent the passage of air and the drainage of the postnasal space, the symptoms are the same as when the closure is complete, the existence of a small opening being, as Bosworth ${ }^{27}$ and Cartaz $^{16}$ observe, of no practical importance.

The degree to which the ears and hearing become affected depends largely on the extent to which the tubal orifice or the tubal muscles become involved, and is entirely independent of the closure of the postnasal space below. Dunbar Roy ${ }^{32}$ reports a case of complete syphilitic occlusion of the postnasal opening in a man 65 years of age, in which the hearing was unaffected, being quite acute for a man of his age. Barbon ${ }^{33}$ reports a

30. Paul: Arch. f. klin. Chir., vii, 199

31. Hajek: Internat. klin. Kundschau, 1892, vi, 1385

32. Roy, Dunbar: Alabama Med. Jour., 1903, p. 556.

33. Arcb. internat de laryngol, 1893, vi, 70 . 
patient almost totally deaf, in whom the hearing was restored by the liberation of the adhesion and re-establishment of nasal respiration; but on the re-formation of the adhesions and closure of the postnasal opening deafness immediately returned. 'This Barbon ascribed to the rarefication of the air in the middle ear. In a similar case Martin ${ }^{33}$ overcame this rarefication of the air in the middle ear and restored the hearing by establishing an opening through the membrana tympani.

These cases are accounted for by the fact that the irifiltration has caused no obstruction of the Eustachian tube or paralysis of the tubal dilators, as mentioned by Bosworth. ${ }^{27}$ In other cases deafness results from the simple closure of the postnasal space and cutting of nasal respiration.

The voice, which is nasal in tone and sometimes almost unintelligible, may occasionally be comparatively unaffected, as in cases reported by Hartmann, ${ }^{34}$ Cartaz $^{35}$ and Mauriac. ${ }^{36}$

The characteristics of the adhesions differ according to the various causes. Those resulting from syphilitic ulcerations are dense and fibrous, the vascular structures being almost entirely destroyed; while those resulting from purely inflammatory conditions are mainly muscular, containing very little fibrous tissue, or there may be simply an adherence of the mucous surfaces. The adhesions are very variable in thickness and extent, from a

- simple web or band-like union to a complete union of the entire parts, often extending to the vault and including both nasal passages. In some cases the contraction of the postnasal passage above the adhesion forms a serious barrier to nasal breathing after the adhesions of the palate have been liberated. Rice ${ }^{37}$ mentions this fact and also the formation of new connective tissue to replace the destroyed tissue, amounting in some cases to actual hypertrophy, which diminishes the diameter of the pharynx in all directions. This condition, he very truly says, compromises the success of operative measures to a very large degree.

The extent to which the deep muscular structures are altered in these cases of destructive ulceration is illustrated by the results of postmortem examinations which were conducted by Dr. William Turner, ${ }^{38}$ of Edinburgh. In these cases he found the deep muscular structures of the postpharyngeal wall almost wholly altered; the muscular fibers of the superior and the upper portion of the middle constrictor muscles were entirely replaced by connective tissue, while the muscles of the palate remained unchanged.

\section{TREATMENT}

In the treatment of these conditions it is important, as Lieven ${ }^{39}$ states, to delay any operative procedures for the relief of the adhesion until all ulceration or inflammation has completely subsided. Much can be done, however, by timely recognition of the conditions that may cause adhesions by means of both local and constitutional treatment. It is, however, only in the early stages of syphilitic manifestations in the nose and throat, before the tissues have broken down, that constitutional treatment is of avail. In these cases this treatment should be pushed most vigorously. The iodids should at once be given in the largest doses, diminished if necessary rather than to be obliged to increase them, in order

34. Hartmann: Versamml. notd-deutsch. Ohrenaerzte in Berlin, April 22,1889

35. Cartaz: Arch. internat. de laryngol., 1893, vi, 81.

36. Mauriac: La syphilis pharyngo-nasale, Paris, 1877, p. 21.

37. Hice: Tr. Am. Lalyngol. Assn., 1895, p. 110

38. Turner, W. Edinburgh Med, Jour., Januly 1860, p. 612

39. Lieven: Mïnchen. med. Wchnschi., 1895, xlii, 489. to overwhelm and head off the activity of the virus before breaking down of the tissues has taken place. After ulceration has occurred they can only arrest it, and, as Schadle ${ }^{40}$ says, "so far as the synechia is concerned, total closure is the result regardless of antisyphilitic treatment."

Previous to the days of laryngoscopy and the rhinoscopic mirror so little was known regarding lesions of the throat that these conditions were little understood; but since that time the etiology and characteristic condi-. tions attending palatal adhesions have been generally well known, although it has been only during the past two decades that any real progress has been made in their successful treatment. The chief difficulty, however, does not reside in the operation of liberating the palate. but in maintaining the opening during the process of healing. Verneuil"1 very aptly says, "Nothing is easier than the liberation of the adhesions, but nothing more difficult than to prevent their reproduction." So dis. couraging have been the results that Cartaz $^{42}$ has ques. tioned the advisability of attempting the unsatisfactory task required in most of these cases.

The various methods employed for dealing with this condition are by (1) mechanical dilators; (2) caustics; (3) permanent obturators; (4) suturing; (5) plastic operations.

The usual method of liberating these adhesions is with the rectangular knife or scissors, a sound or probe being introduced through the nose and the incision made at the point where the palate is made to belly by the pressure of the sound. Dieffenbach ${ }^{43}$ used curved scisson's and maintained the opening with gauze strips. Later he used charpie tampons as a packing. Hajek ${ }^{\mathbf{4 4}}$ adopted a method of repeated incisions and repeated stretching by packing the wound with gauze. The complete liberation of the palate he prolonged over several sittings. Hajek $^{45}$ has since (in 1897) constructed a dilator similar to Frankel's nasal speculum, having two blades turned up at the ends for inserting behind the uvula and palate. It is dilated by turning a screw until the opening is stretched to its fullest capacity and the patient is taught to use it himself. Moritz Schmidt ${ }^{46}$ used Hajek's method of making incisions on each side of the uvula and stretched the openings with the lead sounds of Lublinski, held in place for one hour daily.

Elsberg ${ }^{47}$ separated the parts by means of a blunt staphylorrhaphy knife, then forcibly dilated with the finger, and had the patient use daily a hard rubber palate-retractor to prevent readhesion. Schadle ${ }^{\mathbf{4 8}} \mathrm{em}$ ployed a strip of iodoform gauze two inches wide and fifteen inches long, divided throughout, excepting $\mathbf{a}$ short portion in the center. The upper ends were passed through the nostrils, respectively, until the crotch cams against the posterior extremity of the septum narium: the other ends were brought out through the mouth and tied separately over the upper lip to the upper endis of the tape, sufficiently tight to pull the palate forcibly forward. This was changed daily and worn for several weeks until healing had taken place. The use of rubber bands and ligatures, passed out through the nose and mouth and tied over the jaw, has been adopted by many.

40. Schadle: St. Paul Med. Jour., 1906, viii, 129.

41. Verneuil : Brill. et mém. soc. đé chir., 1876, n. s. ii, 310 .

42. Cartaz: Arch, internat. de laryngol., vi, 66 .

43. Dieffenbach : Operative Chirurgie, i.

44. Hajek: Internat. klin. Rundschau, 1892, vi, 1386

45: Hajek: Allg. Wien. med. Ztg., 1897, xlii, 13.

46. Schmidt, M. : Krankheiten der oberen Inftwege, 1894

47. Rice: Tr. Am. Laryngol. Assn., 1885, p. 112.

48. Schadle, J: E. : Total Adherent Soft Palate. The Jovrnd. A. M. A., 1894, xxiii, 457 . 
The readiness with which cicatricial tissue reunites when separated and the persistence with which this scar tissue contracts led Coulson, ${ }^{49}$ in 1862 , to dissect out the cicatrix, a method which was also employed by Ried $^{8}$ in 1864 and Rothenberg ${ }^{51}$ in 1876 . He first separated the palate above the line of the scar and dissected out the cicatrix with forceps and scalpel. This plan was successfully adopted by Hamilton ${ }^{52}$ in the case of a woman aged 32. There had been obstruction of the nose since she was 14 years of age, following ulcerated throat at 12 , due to hereditary syphilis. There were no signs of adhesions until by the use of the rhinoscope and by digital examination it was found that about half an inch up, the posterior surface of the palate was completely adherent to the posterior pharyngeal wall. The uvula was first freed and later on the cicatricial tissue was removed en masse. The opening was dilated with the finger and with Griffin's dilato: and remained patent. The patient's health was immediately greatly improved.

One of the principal things that discouraged free liberation of the adherent palate was the fear of hemorrhage, for the control of which von Dionisio ${ }^{53}$ used a rubber ball inflated like a Barnes dilator. To obviate the danger that may attend such hemorrhage T. Gilbert Smith, ${ }^{54}$ of London, advised that a preliminary tracheotomy be performed, and even as late as 1903 Tillev'55 reports a case in which he performed tracheotomy betore liberating the palate. The small amount of bleeding, however, convinced him of the folly of the procedure, which he said he would not undertake again.

The introduction of the galvanic cautery by Voltolini promised to add an important method in the treatment of these cases, as it not only obviated the danger of hemorrhage but gave hope that contraction would not readily take place after the burning. These hopes, however, proved groundless, for it was found that contraction took place more readily and more firmly after cauterization than after cutting, or, more particularly, after tearing the parts away, as was practiced by Verneuil. ${ }^{41}$

In 1883 Drs. Smith and Delavan ${ }^{56}$ brought forward the use of monochloracetic acid in the treatment of this condition. Two years before, Dr. Smith called attention to the peculiarity of the caustic action of monochloracetic acid, in that the eschar remained attached until eicatrization had taken place beneath it. On account of this peculiar action Dr. Delavan applied it to the cut surfaces after the adherent velum had been liberated, and, although the surfaces remained in contact afterward, the healing took place beneath before the eschar separated and the operation proved a success. Schadle $^{48}$ also reports the successful use of the acid in a similar case. While the immediate result in these cases was most excellent, the ultimate result of the cases is not stated. In one of the cases which I have to relate the immediate result was most encouraging, but subsequently contraction gradually took place from the sides and progressed toward the center until the opening was finally closed, excepting a small passage in the center.

The uncertainty of all known measures to maintain a free opening after liberation of the palate led different operators to adopt the method of suturing the parts.

49. Coulson: Lancet. I ondon, 1862 , ii, 529

51. Rothenberg: Wiencr med. Presse, 1876, No. 33

52 Hamilton: Montreal Med. Jour. 1895, xxii, 191

53. Von Dionisio: Monatschr. f. Ohienh., 1892, p. 210.

54. Smith, T. G.: Brit. Med. Jour, 1880, ii, 588. 71 .

56. Smith and Delavan: Tr. Am. Laryngol. Assn., 1883, p. 187.
Dieffenbach ${ }^{43}$ passed ligatures through the soft palate, drew it forward as far as possible and held it away from the pharyngeal wall by passing the ligatures out of the mouth and fastening them around thc ears. Later he sutured the edges of the incision together after division, but found it an exceedingly difficult procedure, and, as Kummel ${ }^{57}$ remarks, for less skilful operators this suturing would hardly be possible. He also turned the cut surface backward on itself and stitched it there to still further prevent adhesions.

A more complicated method of suturing the palate was devised by von Lesser, ${ }^{58}$ of Leipsic, in 1879 . $\mathrm{By}$ his method the free portion of the palate was split parallel to its surface, and the posterior flap, being thus entirely denuded, was brought forward and rolled up under the anterior flap. The anterior flap was then split in the center, and also liberated at the sides, an.l was turned back over the rolled up posterior flap, so as to cover the denuded membrane; in this way reunion of the velum to the posterior pharyngeal wall was to be prevented.

These methods of suturing together the mucous surfaces of the palate are feasible only in those cases in which the attachment of the palate is confined to its free border, for in cases of more extensive attachment sufficient mucous membrane is not available to cover the denuded surface.

The failure of all these different methods to maintain a permanently free opening in a very large majority of cases, no matter in what manner the palate, was liberated, led to the adoption of a permanent mechanical obturator to be worn continuously or held in the opening for a long time until healing was complete and the tendency to contraction overeome by the absorption of the cicatrix or of the plastic exudate.

In order to accomplish this result Cook, ${ }^{59}$ in $18 \% 3$, devised the original plan of suspending a lead plate, made of a suitable size to fit the aperture after the palate had been liberated, behind the veil of the palate, by two strings passed through the nostrils. This the patient wore continuously for six weeks or more, as the case might require, without interfering with deglutition, and it successfully prevented readhesion. Later on hard rubber was substituted for the lead plates by different operators, as von Beregszaszy, ${ }^{60}$ Hajek, ${ }^{61}$ Barajas, ${ }^{62}$ the plates being made to completely fill the aperture and suspended by string passed through the nose and tied in front of the nostrils.

The principal objection to the permanent obturator in the posterior nares was found to be the cutting off of nasal respiration. This objection was obviated by Lucas-Championnière $^{63}$ in 1876 , who inserted a silver tube, held in place with gold wire fastened to the teeth. Kuhn, ${ }^{64}$ in 1892, constructed a fenestrated obturator or tube made of hard rubber, which was held in place by bcing attached to a dental plate, the plate and tule being constructed of one piece. This method was alsn successfully adopted by Couetoux ${ }^{65}$ in 1893. Kollbrunner, ${ }^{66}$ of Strassburg, in 1896, and later on McDou-

\footnotetext{
57. Kummel : von Bergman's System of Surgery, i, 902.
58. Von Lesser : Berl. klin. Wchnschr., No. 23, 1879.

59. Cook: Med. and Surg. Reporter, Philadelphia, 1873, xxviii, 203 .

60. Von Beregszaszy: Internat. klin. Rundschau, 1888, No. 23

61. Hajek: Internat. klin. Rundschau, 1892, vi, 1387.

62. Barajas : Rev. hebd. de laryngol, 1907, ii, xxvii, 459.

63. Lucas-Championniêre: Ann. d. mal. de l'oreille et du larynx 1876 , p. 88 .

64. Kuhn: Monatschr. f. Obrenh., 1892, xxvi, 189. 856.

66. Kollbrunner : Strassburg, C. Goeller, 1896.
} 
gall, ${ }^{67}$ in 1903, described the same method as "a new method of dealing with adherent soft palates," without apparently knowing that it had been employed and published before. The only difference in McDougall's device was that he used a metal tube and plate soldered at one end to the patient's tooth-plate.

It is interesting to note that Schadle ${ }^{68}$ in 1906 , without knowing of the existence of these previous devices, constructed one of hard rubber, the tube and toothplate being made of one piece, the same as the one devised by kuhn.

The permanent relief this device afforded and the little discomfort caused by it is, in many cases, highly gratifying. The only drawbacks are the nasal tone it gives to the roice and, in some cases, the fact that, on swallowing, the food is sometimes forced into the posterior nares, owing to the inability of the patient to close the epipharyngeal space.

The most decided step in advance in the treatment of palatopharyngeal adhesions, however, was taken by Nichols ${ }^{49}$ when, in a paper before the New York Academy of Medicine on "A Method of Correcting Adhesions Between the Soft Palate and the Pharyngeal Wall," he proposed the plan of introducing silk sutures at the side of the palate and allowing the sutures to remain in situ until a healed channel had taken place around them. The palate is then liberated between these two channels, great care being taken not to wound the outer wall of the channel.

In the discussion following Nicholl's paper, Rice of New York remarked: "I do not think Dr. Nicho]s is overestimating the value of his method, for it is the first scientifically useful operation yet devised to cover the special requirements."

This method is similar to that proposed by Rudtorffer for the treatment of webbed fingers by securing a healed opening at the base or angle of the adhesion before the fingers are liberated. For this Rudtorffer used lead buttons, and afterward silver or gold rings.

This operation of Nichols is especially adapted to cases in which the adhesions are limited to the border of the velum, it being inapplicable to adhesions high up behind the palate. In three cases I have employed his method with most gratifying results, modifying it only by substituting silver wire for the silk. Figures 1 and 2 illustrate the particular methods $I$ adopted in introducing the silver wire in the different cases. In two cases a double ring or loop was used, one on each side, each one passing out through the central opening, as shown in Figure 1. In the third case but one ring or loop of wire was used, which was so introduced as to pass entirely around the adherent portion in the center, as shown in Figure 2. In a fourth case this method failed, owing to the thickness of the adhesions. In this case I devised a plan of covering the raw surfaces at the outer angles with flaps of mucous membrane taken from the neighboring parts at the sides. These flaps were made of sufficient length to cover the entire extent, vertically, of the liberated surfaces and were stitched in place with sutures passed directly through the palate.

The details are more fully described in the report of the case wlich follows.

CASE 4.-History.-A woman, aged 24, was referred to me in May, 1908, for an operation on an adherent. palate. The occlusion was complete except for a small opening in the center through which a slender silver probe could be passed.

67. McDougall : Liverpool Med.-Chir. Jour.. 1903, xxili, 295.

68. Schadle: St. Paul Med. Jour., 1906. viii, 127.

69. Nichols: New York Med. Jour., 1890, li, 219.

70. Frice: New York Med. Jour, 1890, 11, 220.
This condition was the result of traumatism that had been produced in an attempt to excise the tonsils one year before. The operation had been done under ether, which the patient took very badly. There had also been much bleeding which so obscured the field of operation that the posterior pharyngeal wall was extensively lacerated and the posterior pillars of the fauces, the uvula, and much of the border of the soft palate were cut away.

Treatment.-There was much thickening and induration of the tissues and the adhesion was quite broad. I succeeded, however, with some difficulty in introducing the sutures at the sides, employing two as in the previous cases. At the time I decided to liberate the adhesion I thought I had succeeded in obtaining a healed opening around the wire all the way through, but on operating it proved that, owing to the inflammatory thickening resulting from the operation, the lealing had extended but little beyond the mucous membrane. Tlis method was therefore certain to prove a failure and accord. ingly some other expedient must be resorted to. It was also certain that attempts to prevent reunion of the parts by plates held in situ would be futile and that a successful result must be obtained in some other manner. My previous experience in plastic work, however, eame to my rescue by suggesting the covering of this raw surface with mucous mem. brane. This proved in every way successful.

Operation.-As it was necessary to cover but one surface of this opening the anterior or palatal side was most available. In order to secure the mucous membrane for this purpose a broad flap was taken from the side of the palate and inside of the cheek, including sufficient submucous connective tissue to assure its vitality. This flap was then brought down and turned backward and upward around the outer and lower border of the soft palate, and stitched at the sides and the free border through it to the palate along the upper end of the flap that had been turned up behind the palate was stitched to the latter with sutures passed directly through the palate. Complete union of this flap took place and on healing there was no undue contraction at the site of these flaps, nor was there the slightest tendency for the readherence of the soft palate to the pharynx at any point, all of which was very gratifying. I did not attempt to cover the center of the soft palate with mucous membrane, it hung so free from the pharynx that adhesion of the two surfaces could not readily take place. I should also mention that the surfaces from which the flaps had been taken were speedily covered with mucous membrane and soon all traces of them disappeared. The central portion of the palate was much thickened, and this thickened tissue was utilized, by cutting and stitching it into shape, to form a very satisfactory uvula. The levator palati muscles had not been sufficiently injured to impair their function so that by the construction of this new uvula the action of the soft palate, in closing the posterior nares during deglutition and phonation, was completely restored. Figure 3 represents the fauces before the operation. Figure 4 shows the flaps in situ.

Postoperative History.-At the time the patient came under my observation the voice was completely nasal and on account of the necessary mouth-breathing, she was gradually losing flesh and strength and had become exceedingly nervous. After the liberation of the palate and complete restoration of nasal respiration, however, she gained rapidly in flesh and strength, and at the end of three months had completely regained the thirty pounds she had lost during the period above described. A recent report from the patient's husband stated that she had had no trouble with the throat since the operation and that she was very well.

This method of dealing with faucial and palatal adhesion is, I believe, entirely new, since I have found no record of its having been done before, and it is radically different from those proposed by Dieffenbach and von Lesser. It is also a method that cannot fail to be successful in all these cases if the operation is carefully and properly done. While the silver suture method is quite satisfactory in many cases, particularly those in which the adhesion is thin and confined to the border of the patate, still it is slow, tedious, and causes the 
patient some discomfort. It is also lacking in immediate results, so desirable in all surgical operations and in adaptation to all conditions that may be found. On the contrary, with this flap method, no matter how thick or extensive the adhesions may be, it is necessary only to make the flaps of the required size to cover the raw or denuded surface and stitch them carefully in place in order to make the operation in every instance a complete success.

44 Clinton Avenue South.

\section{ABSTRACT OF DISCUSSION}

Dr. W. E. Casselberry, Chicago: Palato-pharyngeal adhesions may vary in extent from a slight distortion devoid of symptoms to a state of fusion into a densely cicatricial mass of the edges and fragments of the soft palate, faucial pillars and pharyngeal wall, which have chanced to survive a preceding destructive ulceration. The nasopharynx is all but closed, ending in a conically contracted cul-de-sac from which ribs of scar tissue taper downward to merge into the twisted boundary of the pharynx. It happens that most of my cases have been of this aggravated type, syphilitic in origin, and apparently far worse than those described. These patients constitute an unfortunate class, devoid of nasal drainage and ventilation, defective in speech, smell and taste, and go the rounds, seeking whom they can trust to relieve them and again losing confidence before the usual method of treatment by repeated forcible divulsion, could possibly culminate in permanent relief. To encourage persistency in the divulsion treatment, having first made or enlarged the opening by incision, I have taught the patients to make self-divulsion by the insertion and expansion of a small adenoid forceps, and I recall one-case in particular in which, after many months' persistence in self-treatment, a serviceable, permanent opening seemed assured. Dr. Roe merits our gratitude for elab. orating the suture method and for the first report of a case successfully treated by an original flap operation. I have been familiar with the suture method for some time, but in my cases, it seemed too unpromising to attempt, the parts being so distorted that one could not tell where to place a suture so that it would be likely to accomplish the desired effect. But, in the class of cases Dr. Roe has illustrated, it certainly is the best operation. With respect to the flap method, Dr. Roe's case having been traumatic and not syph. ilitic in origin, it scarcely indicates that the flap method will be found generally applicable, although certainly of value whenever tissue from which to form a flap is available nearby.

Dr. W. S. Anderson, Detroit: The only successful method I have ever used, and that was very satisfactory in one serious case in which there was membrane all across the nasopharynx, except one small opening, consisted in passing a suture from the throat up into the nasopharynx and cutting off a pillar of tissue; tying that and waiting until a cicatrix had formed around it and then cutting through. Then I put in another ligature and waited, and again cut off that pillar of tissue. By this method in two months I had separated the membranous portion until $X$ had a good-sized opening into the throat, which has remained permanently open for four or five years. The attempts I have made with other methods have failed.

Dr. C. F. WeLty, San Francisco: Six years ago I saw Dr. Jansen do an operation which I will attempt to descrile. There was but a small opening left in the naso-pharynx. The attachment below and above was severed by a curved knife on either side; the mucous membrane from the soft palate, posteriorly and anteriorly, was brought together on either side; the denuded portion of the pharyngeal wall was cut so that it could approximate very well. In this particular case there was a very happy result.

Dr. Roy P. Scholz, St. Louis: Does Dr. Roe cover the wound, on the posterior pharyngeal wall, produced in the operation? In giving the causes for palato-pharyngeal stricture, there was no mention made of that form resulting from malignant growths; possibly for the reason that these forms are rarely dealt with except by radical means. In cases in which the tumor has been excised, or in which it still exists, but for some reason or other, radical removal of the tumor can not be undertaken, this method appears to be applicable. Recently a case came under my care, carcinoma of the palate (far advanced) with much infiltration of the connective tissues surrounding it, leading to almost complete separation of the oral from the nasopharynx. The disturbance made by this stricture was so great that relief had to be given, and for this and similar cases I believe this form of operation very suitable. This form of stenosis is not the result of ulceration or adhesion, but of contraction of the connective tissues deposited in the structure of the pharyngeal wall.

Dr. Dunbar Roy, Atlanta: I have had three of these cases of palato-pharyngeal adhesions and my experience agrees with that of Dr. Casselberry. It is almost impossible to get a flap from anywhere with such an amount of cicatricial tissue.

Dr. W. W. Carter, New York: Does Dr. Roe depend entirely on these rings of silver ulcerating through? Is it possible for them to ulcerate through the portion of tissue included within the ring and what reason would he give that this doesn't reunite with the posterior pharyngeal wall?

Dr. G. W. Mrtchell, Baltimore: I had a case which gave satisfactory results so far as restoration of the function of hearing was concerned. The patient, a young woman of 20 , had complete occlusion of the nasopharynx so that there was no entrance of air through the nose. She had been operated on when nine years old by a New York surgeon who opened the space, and according to her recollection, removed some bone from the back of the nose. The uvula was bound down and adherent on the posterior wall. This was dissected free and then an angular tonsil separator was pushed up behind the velum and rotated from side to side. The opening was then enlarged by divulsion with a curved tonsil scissors. Large rubber drainage tubes were passed through both nostrils into the oropharynx to keep the surfaces separated during healing. Ulceration of septum necessitated its removal, but not before a fairly satisfactory restoration of breathing and hearing.

DR. J. O. RoE, Rochester: The various causes of palatopharyngeal adhesions are detailed in my paper but were omitted in the reading because of the time limit. In cases in which there is extensive destruction of tissue and a proportionate amount of contraction of the passages, so long as there is a free opening from the nares down to the adhesion, a suture can be introduced from below, it can be passed from above downward. I have devised a needle for that purpose, mounted on a long slender flexible shaft. The eye of the needle is near the point and is guarded by a shield for protecting the point when the needle is introduced. When the needle is passed down to the adhesion, the shield is drawn back and the needle forced through into the mouth, when the thread is caught and the needle withdrawn, leaving the thread in situ. This is repeated on the other side, after which the silver wire is substituted for the thread.

Regarding the plastic flap operation, no matter how much induration there is, if an opening down through the nares can be found for the introduction of a sound to act as a guide for the liberation of the adhesion from below upward, this operation can be performed and is far preferable to the silver wire method in such cases, the latter method being only adapted to cases in which the adhesion is narrow and confined to the border of the palate. When the adhesions are very extensive, forming a mass of cicatricial tissue, $I$ liberate them very freely and sometimes it is advisable to cut away a considerable amount of this cicatricial tissue. Then by making the flap amply large to cover the raw surtace and stitching it carefully in place, there need be no fear of not having complete union of the flap in all cases. The flap should be made wide enough to cover about one-half of the surface on each side. The place in the side of the cheek or jaw where it has been found most available for supplying the flap very quickly heals over and is so readily covered by mucous membrane that in a short time scarcely any mark is left, even though the denuded surfaces may have been quite large. The wire does not ulcerate through and there is nothing to cause it to do so. It simply hangs loose in the tissues where introduced until healing has taken place around it. If it should ilcerate through, the operation would be a failure. 